\title{
Asymmetric Allylic Alkylation of Acyclic $\beta$-Keto Esters Catalyzed by Iridium
}

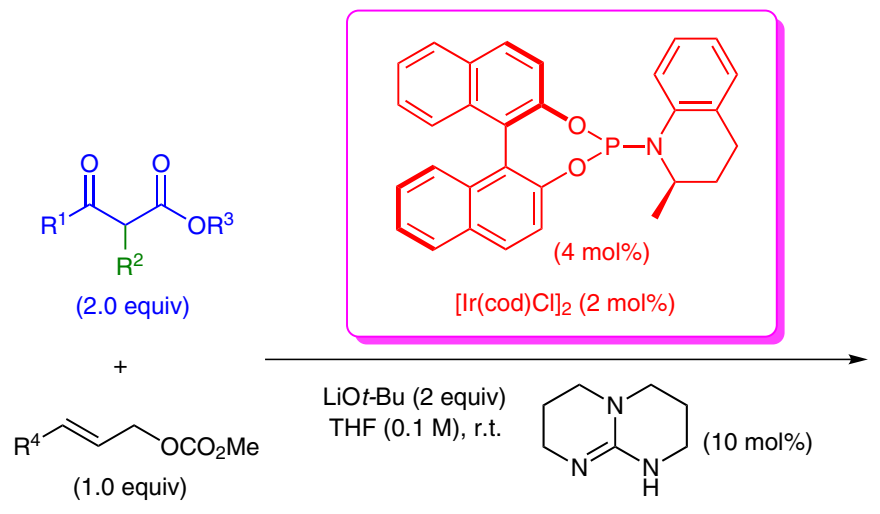<smiles>C=C[C@H](O)C=O</smiles>

26 examples up to $99 \%$ yield up to $>99 \%$ ee dr up to $>99: 1$ b/l up to $99: 1$ b $=$ branched

$(0.10 \mathrm{mmol}$ scale $)$
Category

Metal-Catalyzed Asymmetric

Synthesis and

Stereoselective

Reactions

\section{Key words}

asymmetric allylic alkylation

$\beta$-keto esters

all-carbon

stereocenters

$N$-aryl

phosphoramidites

iridium<smiles>C=CC(c1ccccc1)C(Cl)(C(=O)OCC)C(=O)c1ccccc1</smiles>

$96 \%$ yield, $\mathbf{b} / \mathrm{l}=96: 4$ $>99 \%$ ee, $d r>20: 1$<smiles>C=C[C@H](c1ccccc1)[C@](C)(C(C)=O)C(=O)C1=CCCCC1</smiles>

$85 \%$ yield, b/l $=90: 10$ $99 \%$ ee, $\mathrm{dr}=12: 1$<smiles>C=CC(=O)[C@](Cc1c[nH]c2ccccc12)(C(=O)c1ccccc1)[C@H](CC)c1ccccc1</smiles>

$98 \%$ yield, $\mathbf{b} / \mathrm{l}=95: 5$ $>99 \%$ ee, $d r=7: 1$<smiles>C=C[C@H](c1cccc(OC)c1)[C@@](C)(C(=O)OCC)C(=O)c1ccccc1</smiles>

$99 \%$ yield, $\mathbf{b} / \mathrm{l}=90: 10$ $>99 \%$ ee, $\mathrm{dr}=17: 1$<smiles>C=C[C@H](c1ccc([N+](=O)[O-])cc1)[C@@](C)(C(=O)OCC)C(=O)c1ccccc1</smiles>

$78 \%$ yield, $\mathbf{b} / \mathbf{l}=50: 50$ $93 \%$ ee, $d r=14: 1$
Significance: The asymmetric allylic alkylation belongs to one of the fundamental $\mathrm{C}-\mathrm{C}$ bondformation reactions and a variety of nucleophiles are successfully employed. However, the formation of an all-carbon quaternary stereocenter is still a challenging case. Herein, the authors report an efficient allylic alkylation of acyclic $\beta$-keto esters catalyzed by an Ir-N-aryl-phosphoramidite catalyst. The products bearing vicinal quaternary and tertiary stereocenters are obtained in high yield, regio-, diastereo-, and almost perfect enantioselectivity.
Comment: The substrate scope of the iridiumcatalyzed diastereoselective allylic alkylation covers aryl, heteroaryl and alkenyl substituents on the allyl carbonate electrophile. Interestingly, the regioselective outcome of the reaction (branched vs. linear) is influenced by the substituent's ability to donate or withdraw electron density. In the case of 4-MeOAr, the branched product is formed almost exclusively. Variations on the $\beta$-keto ester moiety are also conducted and a variety of functional groups are tolerated at the $\alpha$ position $\left(R^{2}\right)$, including alkyl, allyl, propargyl, and heteroaryl groups.

SYNFACTS Contributors: Mark Lautens, Marcel Sickert

Dol: 10.1055/s-0033-1340583; Reg-No.: L16613SF 